\title{
Breathe with Touch: A Tactile Interface for Breathing Assistance System
}

\author{
Bin $\mathrm{Yu}^{(\bowtie)}$, Loe Feijs, Mathias Funk, and Jun Hu \\ Industrial Design Department, \\ Technology University of Eindhoven, Eindhoven, The Netherlands \\ \{B. Yu, L. M. G. Fei j., M. Funk, J. Hu\}@TUE. NL
}

\begin{abstract}
Breathing techniques have been widely used as an aid in stress-reduction and relaxation exercises. Most breathing assistance systems present breathing guidance in visual or auditory forms. In this study, we explored a tactile interface of a breathing assistance system by using a shape-changing airbag. We hypothesized that it would help users perform the breathing exercise more effectively and enhance their relaxing experience. The feasibility of the tactile interface was evaluated from three aspects: stress reduction, breathing training and interface usability. The results showed that for most participants, the overall heart rate variability were improved after breathing training. Moreover, "Breathe with Touch" brought users better satisfaction during the exercise. We discuss these results and future design implications for designing tactile interfaces for breathing guidance.
\end{abstract}

Keywords: Tactile interface $\cdot$ Biofeedback $\cdot$ Breathing assistance $\cdot$ Relaxation

\section{Introduction}

In modem society, the pace of life is fast and the competition is fierce. An increasing number of people are suffering from chronic stress in their daily life. Breathing techniques have been widely used in mind-body practices for stress reduction and relaxation [1]. Breathing techniques offer a simple tool to improve the balance of autonomic nervous system, strengthen its capability to adapt to stress and further mitigate the negative effects of stress on the health [2]. With a variety of breathing assistance devices, individuals learn to regulate their breathing into an optimal pattern with the aim of stress reduction. But this is not an easy task for most people to achieve a real relaxed state physically and mentally; because besides an improved breathing skills, the users' psycho-physiologic relaxing experience also affects the stress mitigation. To put it simply, users should also "feel good" during a breathing exercise. Therefore, the interface of breathing assistance device should not only offer an effective breathing guidance, but also a "feeling good" relaxing experience.

In medical applications, breathing guidance is usually presented in graphic or numeric forms, which tend to be technical and performance-oriented. In recent years, several new audiovisual interfaces with more aesthetic qualities have been created for daily use. For instance, Yongqiang Qin et al. developed an immersive breathing training game "Balloon" to train the user to improve breathing pattern [3]. In [4], 
the authors presented "Sonic Respiration" to provide breathing feedback by modifying the quality of musical interface. However, very little work has explored the feasibility of tactile interface for breathing guidance.

The sense of touch enables us to interact with real objects around us, meanwhile, to perceive these interactions. In [5], the authors suggested that the characteristic bidirectional property of touch sense provides a basis to further enhance motor learning and somatic experience. Studies in [6] revealed that tactile feedback could also reduce the perceived workload in learning tasks and enhance the user's feeling of presence. Moreover, stimulating the tactile sense can give people strong relaxing experiences or even emotional experiences, which are beneficial for stress mitigation and health. Therefore, tactile stimuli are often used as a way to reduce stress and make people feel better, such as in massaging techniques and physiotherapy. Tactile feedback is often integrated into multimodal interfaces to enhance the user experience. For example in [7] the authors developed a breathing guidance system to provide the users with an immersive experience through a multimodal interface of auditory, vibratile and light stimuli.

In this study, we aim to investigate whether the tactile interface would help users perform breathing exercise more effectively and enhance user experience during the exercise. We present the concept of "Breathe with Touch": a tactile interface of breathing assistance device that provides breathing guidance through a shape-changing airbag. The airbag inflates and deflates at a specific rhythm to simulate the targeted respiratory pattern. We assume that the changes in the shape of airbag can be mirrored by the user resulting in a better and more relaxing breathing pattern. The tactile interface was evaluated from three aspects: the effect on stress reduction, the efficacy of breathing guidance and the usability. We synthesized the results with valuable qualitative responses from users.

\section{Design and Implementation}

The concept "Breathe with Touch" entails a tactile interface for breathing exercises. By touching the interface, the user follows the shape change of the interface to receive the feedback information. To design the proper form of tactile feedback, we observe the nature of human's breathing movement. Breathing is accompanied by diaphragm fluctuation activities. As an individual inhale, the diaphragm contracts and flattens, causing the expansion of the lungs. Conversely, on exhale, the diaphragm relaxes and moves upward to reduce the space in the chest cavity (see Fig. 1). The lungs are like two air balloons inside of our body. The changes in its shape depend on the airflow.

"Breathe with Touch" simulates human's breathing movements through the shape changes of an inflatable airbag. The expansion and contraction of the lungs are mirrored by the inflation and deflation of the airbag. We assume that this kind of natural mapping between the targeted behavior and the interface could minimize cognitive workload thanks to the intuitive interpretation of the interface. Besides, we think the gradual shape-changing process of airbag could render the breathing guidance in a more soothing way, which helps users slow down their breathing and calm down as well. A hand-sized ellipsoid airbag was made of thermoplastic textile covered by a 


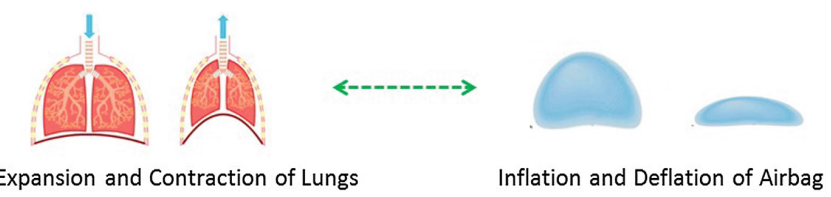

Fig. 1. The shape change of the airbag might be naturally associated with breathing movements

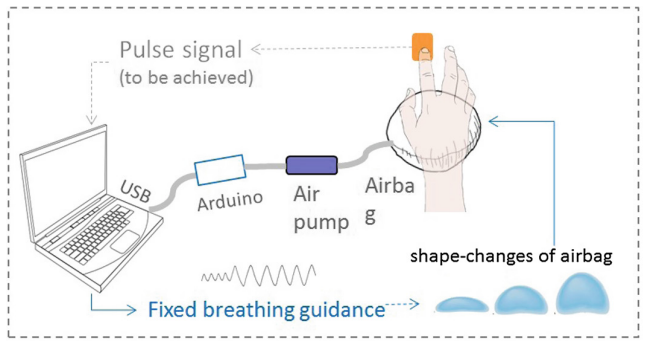

(a).

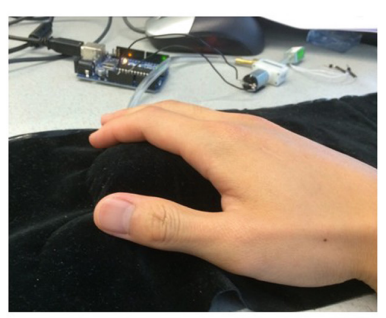

(b).

Fig. 2. (a). Touch Airbag schematic diagram. (b). The user's right hand on the airbag

layer of soft velvet. The user rests her hand on the airbag to "feel" the targeted breathing rhythm (see Fig. 2b).

The breathing guidance is mapped to the airbag in the following way: when the airbag inflates, an inhale activity is implied. When the airbag deflates, an exhale activity is implied. The maximum volume of airbag is around $120 \mathrm{ml}$ that is the same size of a mouse approximately. This enables the user to identify subtle changes of the shape easily and accurately by hand. The sensitive tactile feelings from the hand and fingers ensure that users can receive the guidance precisely as well. An air pump and a solenoid vent valves implement the inflation and deflation of the airbag. During the inflation, the air-pump pumps air into the airbag and the valve is closed. During the deflation, the air-pump stops working and the valve turn opened. Then, with the hand own weight, the air will be pushed out of airbag gently.

In this study, we focus on the design and evaluation of the tactile interface. A feed forward system was built with a pre-set breathing rate of 6 breathing cycles per minute (c/min). According to literature [8], most people could achieve a high HRV level under a respiration of $6 \mathrm{c} / \mathrm{min}$. The airbag starts from the deflated state to inflated state then return to deflated state again. The duration of this inflation/deflation process is $10 \mathrm{~s}$ and this process repeats for the whole training session. As shown in Fig. 2(a), the proposed tactile interface in this work can be embedded into a complete closed-loop biofeedback breathing assistance system in our future research.

\section{Study One: Evaluation of the Effects on Stress Reduction}

We administered the first user study to investigate whether the proposed tactile interface would enhance breathing training and reduce stress effectively. 12 subjects (six females and six males, age range: 25 to 35 ) participated in the study. Each participant 
performed two stress-induced tasks (mathematical test) before and after breathing training. For each task, the physiological data (pulse signals and respiration data) and subjective stress reports were collected (Fig. 3).

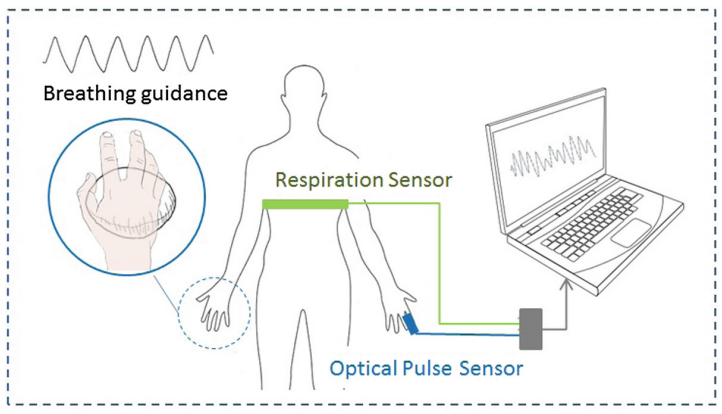

(a).

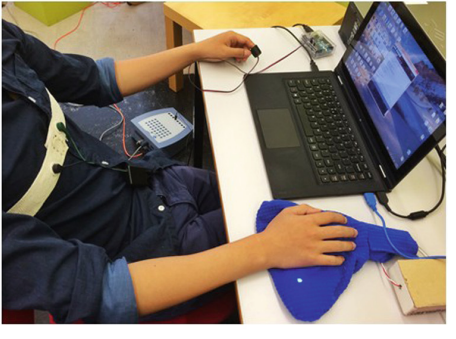

(b).

Fig. 3. (a). The experiment set up (b). Right hand on the airbag

For each participant, A PPG sensor was placed on the left index finger and a respiratory sensor was placed at the abdominal level. Pulse signals were measured by a data acquisition unit developed by our lab, and then beat-to-beat intervals (RR intervals) were calculated and transmitted to a Processing program for data storage. The standard deviation of the beat-to-beat intervals $(S D N N)$ was calculated as the index of HRV. Respiration data was recorded by the ANT system ${ }^{1}$ with a sampling rate of $256 \mathrm{~Hz}$. The participant's stress level were measured by the state component of a Spielberger State-Trait Anxiety Inventory (STAIS) [9].

The experiment followed a procedure as shown in Fig. 4. On arrival at the laboratory, the participants were instructed how to use the breathing assistance system. The pulse sensor and respiration sensor were applied to the participants. Then participants were instructed to relax with their eyes closed for $5 \mathrm{~min}$. After the resting period and without moving, participants were instructed to open their eyes and complete a pre-training mathematical task which lasted 10 min during which time measurements of HRV and respiratory rate were calculated. After the task, participants completed a pre-training STAIS questionnaire. After further 5-min rest with eyes closed, then participants completed a 10-min breathing training session with "Breath with touch". The instructions given to participants were: "Please follow the changes of the airbag to breathe, when the airbag inflates, you should breathe in. When airbag begins to deflate, you should breathe out. This session will last for 10 min." After the training, participants completed a further 10-min mathematical task. Pulse signal and respiratory data were also recorded throughout this period. Then, a post-training STAIS questionnaire was completed.

The HRV, respiration rate and STAIS were calculated in Pre-training and Post-training periods separately. Differences were analyzed using an independent t-test.

\footnotetext{
${ }^{1}$ ANT, the Netherlands, http://www.ant-neuro.com/.
} 


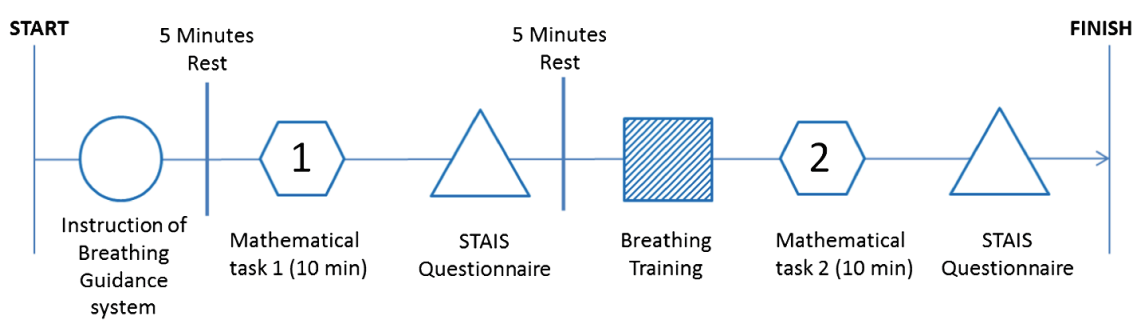

Fig. 4. The experiment procedure

All data are described as means \pm standard deviation (SD). A p-value of $<0.05$ was considered to be statistically significant.

Physiological data were missing from two participants because of technical problems. As the index of HRV, SDNN showed different degrees of increase among all participants after the breathing training, as shown in Fig. 5. The SDNN values of post-training period were significantly higher than pre-training period $(49.5 \pm 14.2 \mathrm{vs}$. $66.3 \pm 20.4$; Pre-training vs. Post-training, $p<0.05$ ). Regarding the results of respiration data, seven participants showed a slower respiration rate during post-training task. However, there were no significant differences before or after training (18 $\pm 6 v s$. $15 \pm 2$ circles; Pre-training vs. Post-training).
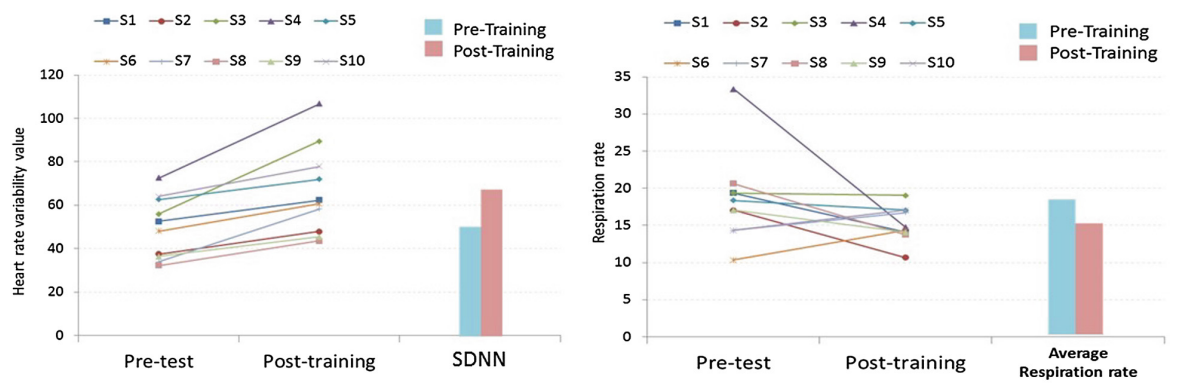

Fig. 5. HRV $(S D N N)$ and respiration rate before and after the breathing training.

Psychometric data from the STAIS questionnaires are shown in Fig. 6. Nine participants reported a lower anxiety level during the post-training mathematics task; however, there were three participants showed a higher anxiety levels (subject \#1, \#4, and \#5). The STAIS scores were not significantly different between Pre-training period and Post-training period ( $46 \pm 11$ vs. $39 \pm 9$ points; Pre-training vs. Post-training).

\section{Study Two: Evaluation of Interface Usability}

As tactile interfaces are seldom used in breathing assistance, we conducted another study to investigate the user's perception on the usability of tactile interface. To gain more insightful feedback and recommendations for further design, ten students with interaction design background (four females and six males, age range: 20 to 35) were 


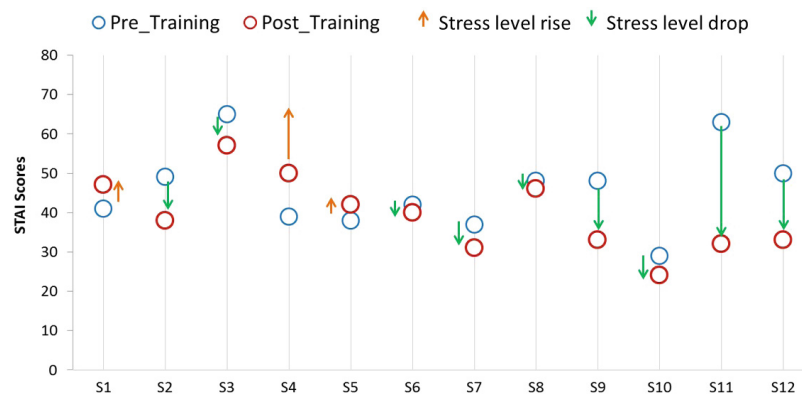

Fig. 6. Scores of STAIS questionnaires pre- and post- the breathing training $(\mathrm{N}=12)$

recruited for this study. All participants complete three 10-min breathing training sessions using the same breathing guidance, but with three different interfaces: visual, auditory and tactile interfaces. The experiment follows a within-subjects design with counter balancing to avoid carry-over effects.

We introduced visual and auditory interfaces for breathing assistance as shown in Fig. 7. In visual interface, an ellipse with varying radius represents the breathing guidance. When the ellipse grows, an inhale process is implied. In auditory feedback, we used the changes in sound volume to present breathing guidance. An increasing sound volume prompted user to breathe in, and the fading sound implied breathing out. The usability of the interface was measured using an adapted Lund's USE Questionnaire [10]. The questionnaire was designed for three dimensions: ease of use, ease of learning and satisfaction. All the questions used a seven-point Likert scale ( $1=$ strongly disagree, 7 = strongly agree).
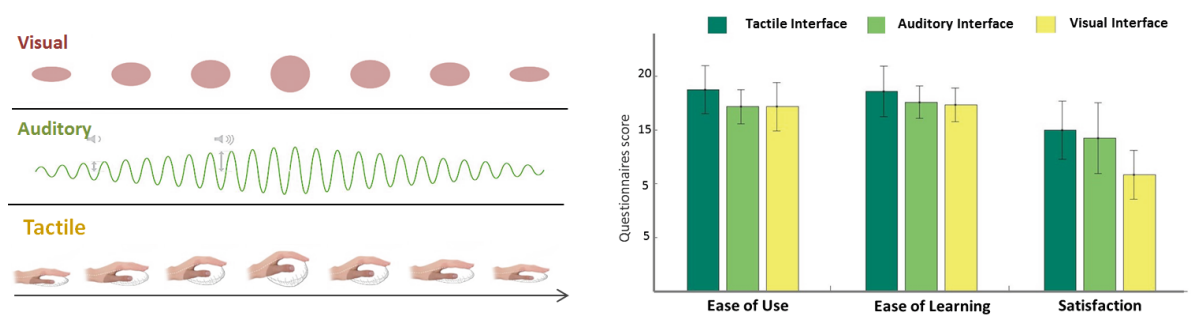

Fig. 7. The results of evaluation of interface usability

The results are shown in Fig. 7. In terms of "Ease of Use", all of three interfaces received high scores; there were no significant differences between tactile, auditory and visual interfaces $(19 \pm 2 v s .17 \pm 2 v s .17 \pm 2$; Tactile vs. Auditory vs. Visual). In terms of "Ease of Learning", there were also no significant differences between three interfaces $(19 \pm 2$ vs. $18 \pm 2$ vs. $17 \pm 2$; Tactile vs. Auditory vs. Visual). In terms of "Satisfaction", the score of visual interface was significant lower than tactile and auditory interfaces $(15 \pm 3,14 \pm 3$ vs. $11 \pm 2$; Haptic, Auditory vs. Visual, respectively, $p<0.05)$. From the open-ended interview, we got more positive feedback about tactile 
interface. More than $70 \%$ participants chose the tactile interface as their favorite interface. Specifically, they expressed a strong interest in working with the tactile interface and emphasized that it was more comfortable due to the touch experience.

\section{General Discussion}

During a breathing training, users need to recognize the breathing guidance and follow it to regulate their breathing. In other words, the breathing training is a learning process, in which the users should take an active role, rather than just being exposed to it. Therefore, in breathing training, although the learning tasks are very simple (i.e. to regulate breathing to a specific rate), some participants still regard it as a serious task, which keep them away from a pure relaxation. We think this might be an interesting "paradox" in the design of self-training system for relaxation. It appeals to us and drive us to think about the interaction design in these products or systems that aim to promote relaxation. The training session requires user's mental effort to achieve optimal training effect, such as improved breathing skills, positive imagination or more concentration. However, such mental effort of learning might leads to new stress.

In this design, we tried to lower the workload and enhance the relaxing experience by using a tactile interface. The touch airbag was used as a tangible communication media between the training system and the user. It is assumed that the user can adapt her breathing movements to an optimal pattern more effortlessly by mirroring the shape changes of the tangible interface. The results of user study confirm that the proposed "natural-mapping" interface could help the users perform breathing exercise more spontaneously. The users do not need to put much effort into understanding the instructions, and the transition between inflation and deflation of airbag might naturally trigger a slow and smooth transition between inhalation and exhalation.

The effectiveness of tactile breathing guidance in aiding relaxation and reducing stress was shown by the results of SAITS self-report. However, there is no significant reduction of stress level during the post-training mathematics task. There might be two possible explanations. For most participants, it was their first time to use breathing assistance system; the unfamiliarity with the system brings about new stresses. We also have reservations about the acute effect of 10-min breathing exercise on stress reduction. Although in some clinical use [11], the minimum time of each training session could be 5 min; a short-period exercise may be repeated several times throughout a day to achieve a greater effect on stress mitigation. From physiological measurements, the results suggested that there was a significant improvement in HRV during the post-training task, which suggests that tactile breathing training could enhance the users'physical ability to adapt to stress.

The users' ratings on the usability of visual, auditory and lighting interface were shown in Fig. 7. The tactile interface shows the potential in improving user experience during the relaxation exercise as seen from significantly higher user ratings on satisfaction. Improvements in user experience were also evidenced by the participants' feedback from the interviews at the end of the experiment. During a breathing training process, repeated breathing instructions become boring easily. This is a major problem of most breathing guidance systems for long-term use. To some extent, the touch airbag 
shifts the focus from the superficial interface to users' own regulating behavior, which helps to relieve users of tedium. Besides, the users thought tactile feedback offers a condition for them to perform breathing training with eyes closed, which also helped relax. They also gave us a lot of insightful recommendations for further design of the interface, for instance, changing the size or position of airbag, integrating the airbag into regular items, and combining tactile and auditory feedback.

\section{References}

1. Gilbert, C.: Clinical applications of breathing regulation. beyond anxiety management. J. Behav. Modif. 27(5), 692-709 (2003)

2. Gevirtz, R.: Resonant frequency training to restore homeostasis for treatment of psychophysiological disorders. J. Biofeedback 27, 7-9 (2000)

3. Qin, Y., Vincent, C.J., Bianchi-Berthouze, N., Shi, Y.: AirFlow: designing immersive breathing training games for COPD. In: CHI 2014 Extended Abstracts on Human Factors in Computing Systems, pp. 2419-2424. ACM (2014)

4. Harris, J., Vance, S., Fernandes, O., Parnandi, A., Gutierrez-Osuna, R.: Sonic respiration: controlling respiration rate through auditory biofeedback. In: CHI 2014 Extended Abstracts on Human Factors in Computing Systems, pp. 2383-2388. ACM (2014)

5. Hale, K.S., Stanney, K.M.: Deriving haptic design guidelines from human physiological, psychophysical, and neurological foundations. J. Comput. Graph. Appl. IEEE 24(2), 33-39 (2004)

6. Gallace, A., Spence, C.: The science of interpersonal touch: an overview. J. Neurosci. Biobehav. Rev. 34(2), 246-259 (2010)

7. Dijk, E.O., Weffers, A.: Breathe with the ocean: a system for relaxation using audio, haptic and visual stimuli. Spec. Symp. EuroHaptics 2010, 50-60 (2011)

8. Vaschillo, E.G., Vaschillo, B., Lehrer, P.M.: Characteristics of resonance in heart rate variability stimulated by biofeedback. J. Appl. Psychophysiol. Biofeedback 31(2), 129-142 (2006)

9. Marteau, T.M., Hilary, B.: The development of a six-item short-form of the state scale of the spielberger state - trait anxiety inventory (STAI). J. Brit. J. Clin. Psychol. 31(3), 301-306 (1992)

10. Lund, A.M.: Measuring usability with the USE questionnaire. J. Usability Interface 8(2), 3$6(2001)$

11. Muench, F.: The portable stresseraser heart rate variability biofeedback device: background and research. J. Biofeedback 36(1), 35-39 (2008) 
Julio Abascal · Simone Barbosa

Mirko Fetter - Tom Gross

Philippe Palanque - Marco Winckler (Eds.)

Human-Computer

Interaction -

INTERACT 2015

15th IFIP TC 13 International Conference

Bamberg, Germany, September 14-18, 2015

Proceedings, Part III

2 Part III

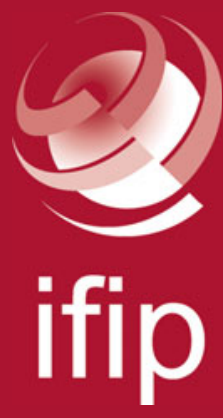

Springer 


\section{Lecture Notes in Computer Science}

Commenced Publication in 1973

Founding and Former Series Editors:

Gerhard Goos, Juris Hartmanis, and Jan van Leeuwen

\section{Editorial Board}

David Hutchison

Lancaster University, Lancaster, UK

Takeo Kanade

Carnegie Mellon University, Pittsburgh, PA, USA

Josef Kittler

University of Surrey, Guildford, UK

Jon M. Kleinberg

Cornell University, Ithaca, NY, USA

Friedemann Mattern

ETH Zurich, Zürich, Switzerland

John C. Mitchell

Stanford University, Stanford, CA, USA

Moni Naor

Weizmann Institute of Science, Rehovot, Israel

C. Pandu Rangan

Indian Institute of Technology, Madras, India

Bernhard Steffen

TU Dortmund University, Dortmund, Germany

Demetri Terzopoulos

University of California, Los Angeles, CA, USA

Doug Tygar

University of California, Berkeley, CA, USA

Gerhard Weikum

Max Planck Institute for Informatics, Saarbrücken, Germany 
More information about this series at http://www.springer.com/series/7409 
Julio Abascal · Simone Barbosa

Mirko Fetter - Tom Gross

Philippe Palanque · Marco Winckler (Eds.)

\section{Human-Computer \\ Interaction - \\ INTERACT 2015}

15th IFIP TC 13 International Conference Bamberg, Germany, September 14-18, 2015 Proceedings, Part III

粤 Springer 


\section{Editors}

Julio Abascal

Universidad del País Vasco/Euskal Herriko

Unibertsitatea

Donostia-San Sebastián

Spain

Simone Barbosa

PUC-Rio

Rio de Janeiro

Brazil

Mirko Fetter

University of Bamberg

Bamberg

Germany
Tom Gross

University of Bamberg

Bamberg

Germany

Philippe Palanque

University Paul Sabatier

Toulouse

France

Marco Winckler

University Paul Sabatier

Toulouse

France

ISSN 0302-9743

ISSN 1611-3349 (electronic)

Lecture Notes in Computer Science

ISBN 978-3-319-22697-2

ISBN 978-3-319-22698-9 (eBook)

DOI 10.1007/978-3-319-22698-9

Library of Congress Control Number: 2015945606

LNCS Sublibrary: SL3 - Information Systems and Applications, incl. Internet/Web, and HCI

Springer Cham Heidelberg New York Dordrecht London

(C) IFIP International Federation for Information Processing 2015

This work is subject to copyright. All rights are reserved by the Publisher, whether the whole or part of the material is concerned, specifically the rights of translation, reprinting, reuse of illustrations, recitation, broadcasting, reproduction on microfilms or in any other physical way, and transmission or information storage and retrieval, electronic adaptation, computer software, or by similar or dissimilar methodology now known or hereafter developed.

The use of general descriptive names, registered names, trademarks, service marks, etc. in this publication does not imply, even in the absence of a specific statement, that such names are exempt from the relevant protective laws and regulations and therefore free for general use.

The publisher, the authors and the editors are safe to assume that the advice and information in this book are believed to be true and accurate at the date of publication. Neither the publisher nor the authors or the editors give a warranty, express or implied, with respect to the material contained herein or for any errors or omissions that may have been made.

Printed on acid-free paper

Springer International Publishing AG Switzerland is part of Springer Science+Business Media (www.springer.com) 


\section{Foreword}

The 15th IFIP TC.13 International Conference on Human-Computer Interaction, INTERACT 2015, was held during September 14-18, 2015, in Bamberg, Germany, organized by the University of Bamberg. The city of Bamberg is proud of its more than 1,000-year-old center. It has more than 2,400 historically listed buildings and became a UNESCO World Cultural Heritage Site in 1993. With 70,000 inhabitants, Bamberg is a small town in the heart of Europe.

The theme of the 2015 edition was "Connection, tradition, innovation." In its relatively short history, the human-computer interaction (HCI) area has experienced impressive development. Theories, methodologies, procedures, guidelines, and tools have been progressively proposed, discussed, tested, and frequently adopted by academia and industry. The protagonists of this development created in a short period of time a scientific and technological tradition able to produce high-quality interaction systems. However, the evolution of the computers and networks pose new challenges to all stakeholders. Innovation, based on tradition, is the only way to face these challenges, even if innovation often requires breaking the tradition. In order to make this process possible, INTERACT 2015 provides diverse and abundant connection opportunities. A multidisciplinary approach is characteristic of the HCI field. INTERACT 2015 aimed to connect all the matters able to contribute to the quality of the future interactions among people and computers.

The series of INTERACT international conferences (started in 1984) is supported by Technical Committee 13 on Human-Computer Interaction of the International Federation for Information Processing (IFIP). This committee aims at developing the science and technology of the interaction between humans and computing devices.

IFIP was created in 1960 under the auspices of UNESCO with the aim of balancing worldwide the development of computer technology and Science. Technical Committee 13 is fully conscious of the social importance of information and communication technologies for our world, today and in the future. Therefore, INTERACT 2015 made efforts to attract and host people from all over the world, and to pay attention to the constraints imposed on HCI by differences in culture, language, technological availability, physical, as well as sensory and cognitive differences, among other dimensions of interest.

INTERACT 2015 gathered a stimulating collection of research papers and reports of development and practice that acknowledge the diverse disciplines, abilities, cultures, and societies, and that address all the aspects of HCI, including technical, human, social, and esthetic.

Like its predecessors, INTERACT 2015 aimed to be an exciting forum for communication with people of similar interests, to foster collaboration and learning. Being by nature a multidisciplinary field, HCI requires interaction and discussion among diverse people with different interests and backgrounds. INTERACT 2015 was directed both to the academic and industrial world, always highlighting the latest developments 
in the discipline of HCI and its current applications. Experienced HCI researchers and professionals, as well as newcomers to the HCI field, interested in the design or evaluation of interactive software, development of new technologies for interaction, and research on general theories of HCI met in Bamberg.

We thank all the authors who chose INTERACT 2015 as the venue to publish their research. This was again an outstanding year for the conference in terms of submissions in all the technical categories.

We received 651 submissions. Of these, the following were accepted: 93 full research papers; 74 short research papers; eight demos; 30 interactive posters; four organizational overviews; three panels; six tutorials; 11 workshops; and 13 doctoral consortium papers.

The acceptance rate for the full papers was $29.6 \%$ and $26.8 \%$ for short papers.

In order to select the highest-quality contributions, an elaborate review system was organized including shepherding of 38 full research papers that went through a second and sometimes a third round of review. That process was primarily handled by the 32 meta-reviewers who willingly assisted and ensured the selection of high-quality full research papers to be presented at INTERACT 2015.

The final decision on acceptance or rejection of papers was taken in a plenary Program Committee meeting held in Tampere (Finland) in February 2015, aimed to discuss a consistent set of criteria to deal with inevitable differences among the large number of reviewers who were recruited and supported by the meta-reviewers. The technical program chairs and the track chairs, the general chairs, and the members of IFIP Technical Committee 13 participated in the meeting.

Special thanks must go to the track chairs and all the reviewers, who put in an enormous amount of work to ensure that quality criteria were maintained throughout the selection process. We also want to acknowledge the excellent work of the co-chairs of the different sections of the conference and the meta-reviewers of the full research paper track.

We also thank the members of the Organizing Committee, especially Mirko Fetter, local organization chair, who provided us with all the necessary resources to facilitate our work. Finally, we wish to express a special thank you to the proceedings publication chair, Marco Winckler, who did extraordinary work to put this volume together.

September 2015

Tom Gross

Julio Abascal

Simone Barbosa

Philippe Palanque 


\section{IFIP TC13}

Established in 1989, the International Federation for Information Processing Technical Committee on Human-Computer Interaction (IFIP TC13) is an international committee of 37 national societies and nine working groups, representing specialists in human factors, ergonomics, cognitive science, computer science, design, and related disciplines. INTERACT is its flagship conference, staged biennially in different countries in the world. From 2017 the conference series will become an annual conference.

IFIP TC13 aims to develop the science and technology of human-computer interaction (HCI) by: encouraging empirical research, promoting the use of knowledge and methods from the human sciences in design and evaluation of computer systems; promoting better understanding of the relation between formal design methods and system usability and acceptability; developing guidelines, models, and methods by which designers may provide better human-oriented computer systems; and, cooperating with other groups, inside and outside IFIP, to promote user orientation and humanization in system design. Thus, TC13 seeks to improve interactions between people and computers, encourage the growth of HCI research and disseminate these benefits worldwide.

The main orientation is toward users, especially non-computer professional users, and how to improve human-computer relations. Areas of study include: the problems people have with computers; the impact on people in individual and organizational contexts; the determinants of utility, usability, and acceptability; the appropriate allocation of tasks between computers and users; modeling the user to aid better system design; and harmonizing the computer to user characteristics and needs.

While the scope is thus set wide, with a tendency toward general principles rather than particular systems, it is recognized that progress will only be achieved through both general studies to advance theoretical understanding and specific studies on practical issues (e.g., interface design standards, software system consistency, documentation, appropriateness of alternative communication media, human factors guidelines for dialogue design, the problems of integrating multimedia systems to match system needs and organizational practices, etc.).

In 1999, TC13 initiated a special IFIP Award, the Brian Shackel Award, for the most outstanding contribution in the form of a refereed paper submitted to and delivered at each INTERACT. The award draws attention to the need for a comprehensive human-centered approach in the design and use of information technology in which the human and social implications have been taken into account. 2007 IFIP TC 13 also launched an accessibility award to recognize an outstanding contribution with international impact in the field of accessibility for disabled users in HCI. In 2013, IFIP TC 13 launched the Interaction Design for International Development (IDID) Award, which recognizes the most outstanding contribution to the application of interactive systems for social and economic development of people in 
developing countries. Since the process to decide the award takes place after papers are submitted for publication, the awards are not identified in the proceedings.

IFIP TC 13 also recognizes pioneers in the area of HCI. An IFIP TC 13 pioneer is one who, through active participation in IFIP Technical Committees or related IFIP groups, has made outstanding contributions to the educational, theoretical, technical, commercial, or professional aspects of analysis, design, construction, evaluation, and use of interactive systems. IFIP TC 13 pioneers are appointed annually and awards are handed over at the INTERACT conference.

IFIP TC13 stimulates working events and activities through its working groups (WGs). WGs consist of HCI experts from many countries, who seek to expand knowledge and find solutions to HCI issues and concerns within their domains, as outlined here.

WG13.1 (Education in HCI and HCI Curricula) aims to improve HCI education at all levels of higher education, coordinate and unite efforts to develop HCI curricula and promote HCI teaching.

WG13.2 (Methodology for User-Centered System Design) aims to foster research, dissemination of information and good practice in the methodical application of HCI to software engineering.

WG13.3 (HCI and Disability) aims to make HCI designers aware of the needs of people with disabilities and encourage development of information systems and tools permitting adaptation of interfaces to specific users.

WG13.4 (also WG2.7; User Interface Engineering) investigates the nature, concepts, and construction of user interfaces for software systems, using a framework for reasoning about interactive systems and an engineering model for developing user interfaces.

WG 13.5 (Resilience, Reliability, Safety, and Human Error in System Development) seeks a framework for studying human factors relating to systems failure, develops leading-edge techniques in hazard analysis and safety engineering of computer-based systems, and guides international accreditation activities for safety-critical systems.

WG13.6 (Human-Work Interaction Design) aims at establishing relationships between extensive empirical work-domain studies and HCI design. It will promote the use of knowledge, concepts, methods, and techniques that enable user studies to procure a better apprehension of the complex interplay between individual, social, and organizational contexts and thereby a better understanding of how and why people work in the ways that they do.

WG13.7 (Human-Computer Interaction and Visualization) aims to establish a study and research program that will combine both scientific work and practical applications in the fields of HCI and visualization. It will integrate several additional aspects of further research areas, such as scientific visualization, data mining, information design, computer graphics, cognition sciences, perception theory, or psychology, into this approach.

WG13.8 (Interaction Design and International Development) are currently working to reformulate their aims and scope. 
WG13.9 (Interaction Design and Children) aims to support practitioners, regulators, and researchers to develop the study of interaction design and children across international contexts.

New Working Groups are formed as areas of significance to HCI arise. Further information is available on the IFIP TC13 website: http://ifip-tc13.org/ 


\section{IFIP TC13 Members}

\section{Officers}

\section{Chair}

Jan Gulliksen, Sweden

Vice-chair

Philippe Palanque, France

Vice-Chair for WG and SIG

Simone D.J. Barbosa, Brazil

\section{Country Representatives}

\author{
Australia \\ Henry B.L. Duh \\ Australian Computer Society \\ Austria \\ Geraldine Fitzpatrick \\ Austrian Computer Society

\section{Belgium} \\ Monique Noirhomme-Fraiture \\ Fédération des Associations \\ Informatiques de Belgique

\section{Brazil} \\ Raquel Oliveira Prates \\ Brazilian Computer Society (SBC)

\section{Bulgaria} \\ Kamelia Stefanova \\ Bulgarian Academy of Sciences
}

\section{Canada}

Heather O’Brien

Canadian Information Processing Society

\section{Chile}

Jaime Sánchez

Chilean Society of Computer Science

\section{Croatia}

Andrina Granic

Croatian Information Technology

Association (CITA)
Treasurer

Anirudha Joshi, India

Secretary

Marco Winckler, France

Webmaster

Helen Petrie, UK

\section{Cyprus}

Panayiotis Zaphiris

Cyprus Computer Society

\section{Czech Republic}

Zdeněk Míkovec

Czech Society for Cybernetics \& Informatics

\section{Denmark}

Torkil Clemmensen

Danish Federation for Information

Processing

\section{Finland}

Kari-Jouko Räihä

Finnish Information Processing

Association

\section{France}

Philippe Palanque

Société des Electriciens et des

Electroniciens (SEE)

\section{Germany}

Tom Gross

Gesellschaft fur Informatik

\section{Hungary}

Cecilia Sik Lanyi

John V. Neumann Computer

Society 


\section{Iceland}

Marta Kristin Larusdottir

The Icelandic Society for Information Processing (ISIP)

\section{India}

Anirudha Joshi

Computer Society of India

\section{Ireland}

Liam J. Bannon

Irish Computer Society

Italy

Fabio Paternò

Italian Computer Society

\section{Japan}

Yoshifumi Kitamura

Information Processing Society of Japan

\section{Korea}

Gerry Kim

KIISE

\section{Malaysia}

Chui Yin Wong

Malaysian National Computer Confederation

\section{The Netherlands}

Vanessa Evers

Nederlands Genootschap voor Informatica

\section{New Zealand}

Mark Apperley

New Zealand Computer Society

\section{Nigeria}

Chris C. Nwannenna

Nigeria Computer Society

\section{Norway}

Dag Svanes

Norwegian Computer Society

\section{Poland}

Marcin Sikorski

Poland Academy of Sciences

\section{Portugal}

Pedro Campos

Associação Portuguesa para o Desenvolvimento da Sociedade da Informação (APDSI)

\section{Slovakia}

Vanda Benešová

The Slovak Society for Computer Science

\section{South Africa}

Janet L. Wesson

The Computer Society of South Africa

Spain

Julio Abascal

Asociación de Técnicos de Informática (ATI)

\section{Sweden}

Jan Gulliksen

Swedish Computer Society

\section{Switzerland}

Solange Ghernaouti

Swiss Federation for Information

Processing

\section{Tunisia}

Mona Laroussi

Ecole Supérieure des Communications De Tunis (SUP'COM)

\section{UK}

Andy Dearden

British Computer Society (BCS)

\section{USA}

Gerrit van der Veer

Association for Computing Machinery (ACM) 


\section{Expert Members}

Nikos Avouris (Greece)

Simone D.J. Barbosa (Brazil)

Peter Forbrig (Germany)

Joaquim Jorge (Portugal)

Paula Kotzé (South Africa)

Masaaki Kurosu (Japan)

\section{Working Group Chairs}

WG13.1 (Education in HCI and HCI Curricula)

Konrad Baumann, Austria

WG13.2 (Methodologies for User-Centered System Design)

Marco Winckler, France

WG13.3 (HCI and Disability)

Helen Petrie, UK

WG13.4 (also 2.7) (User Interface Engineering)

Jürgen Ziegler, Germany

WG13.5 (Resilience, Reliability, Safety and Human Error in System

Development)

Chris Johnson, UK
Gitte Lindgaard (Australia)

Zhengjie Liu (China)

Fernando Loizides (Cyprus)

Dan Orwa (Kenya)

Frank Vetere (Australia)
WG13.6 (Human-Work Interaction Design)

Pedro Campos, Portugal

WG13.7 (HCI and Visualization)

Achim Ebert, Germany

WG 13.8 (Interaction Design and International Development)

José Adbelnour Nocera, UK

WG 13.9 (Interaction Design and Children)

Janet Read, UK 


\section{Conference Organizing Committee}

General Conference Co-chairs

Tom Gross, Germany

Julio Abascal, Spain

\section{Full Papers Chairs}

Simone D.J. Barbosa, Brazil

Philippe Palanque, France

\section{Short Papers Co-chairs}

Fabio Paternò, Italy

Kari-Jouko Räihä, Finland

\section{Posters and Demos Co-chairs}

Stephen Brewster, UK

David McGookin, UK

Organization Overviews Co-chairs

Melanie Fitzgerald, USA

Kori Inkpen, USA

\section{Panels Co-chairs}

Anirudha N. Joshi, India

Gitte Lindgaard, Australia

\section{Open Space Co-chairs}

Christoph Beckmann, Germany

Achim Ebert, Germany

\section{Tutorials Co-chairs}

Christoph Beckmann, Germany

Regina Bernhaupt, France

\author{
Workshops Co-chairs \\ Christoph Beckmann, Germany \\ Víctor López-Jaquero, Spain
}

Doctoral Consortium Co-chairs

Geraldine Fitzpatrick, Austria

Panayiotis Zaphiris, Cyprus

\section{Proceedings Chair}

Marco Winckler, France

\section{Madness Co-chairs}

Artur Lugmayr, Finland

Björn Stockleben, Germany

Tim Merritt, Denmark

\section{Local Organization Co-chairs \\ Mirko Fetter, Germany \\ Claudia Tischler, Germany}

\section{Student Volunteers Co-chairs}

Robert Beaton, USA

Sascha Herr, Germany

\section{Program Committee}

\section{Meta-reviewers}

Birgit Bomsdorf, Germany

Gaëlle Calvary, France

José Campos, Portugal

Pedro Campos, Portugal

Luca Chittaro, Italy

Torkil Clemmensen, Denmark

Paul Curzon, UK

Achim Ebert, Germany

Peter Forbrig, Germany

Michael Harrison, UK 
Anirudha Joshi, India

Denis Lalanne, Switzerland

Effie Law, UK

Célia Martinie, France

Laurence Nigay, France

Monique Noirhomme, Belgium

Fabio Paternò, Italy

Helen Petrie, UK

Antonio Piccinno, Italy

Aaron Quigley, UK

Kari-Jouko Räihä, Finland

Virpi Roto, Finland

\section{Reviewers}

José Abdelnour-Nocera, UK

Al Mahmud Abdullah, Australia

Silvia Abrahão, Spain

Funmi Adebesin, South Africa

Ana Paula Afonso, Portugal

David Ahlström, Austria

Pierre Akiki, Lebanon

Deepak Akkil, Finland

Hannu Alen, Finland

Jan Alexandersson, Germany

José Carlos Bacelar Almeida, Portugal

Florian Alt, Germany

Julian Alvarez, France

Junia Coutinho Anacleto, Brazil

Leonardo Angelini, Switzerland

Craig Anslow, New Zealand

Mark Apperley, New Zealand

Nathalie Aquino, Paraguay

Liliana Ardissono, Italy

Carmelo Ardito, Italy

Oscar Javier Ariza Núñez, Germany

Myriam Arrue, Spain

Ilhan Aslan, Austria

Simon Attfield, UK

Nikolaos Avouris, Greece

Chris Baber, UK

Myroslav Bachynskyi, Germany

Jonathan Back, UK

Gilles Bailly, France

Liam Bannon, Ireland
Luciana Salgado Cardoso de Castro, Brazil

Paula Alexandra Silva, Ireland

Frank Steinicke, Germany

Simone Stumpf, UK

Allistair Sutcliffe, UK

Jean Vanderdonckt, Belgium

Gerhard Weber, Germany

Astrid Weiss, Austria

Marco Winckler, France

Panayiotis Zaphiris, Cyprus
Emilia Barakova, The Netherlands

Javier Barcenila, France

Louise Barkhuus, USA

Barbara Rita Barricelli, Italy

Valentina Bartalesi, Italy

Mohammed Basheri, Saudi Arabia

Christoph Beckmann, Germany

Yacine Bellik, France

Vanda Benešová, Slovak Republic

Kawtar Benghazi, Spain

David Benyon, UK

François Bérard, France

Regina Bernhaupt, Austria

Karsten Berns, Germany

Nadia Berthouze, UK

Raymond Bertram, Finland

Mark Billinghurst, New Zealand

Dorrit Billman, USA

Silvia Amelia Bim, Brazil

Fernando Birra, Portugal

Renaud Blanch, France

Ann Blandford, UK

Mads Boedker, Denmark

Davide Bolchini, USA

Birgit Bomsdorf, Germany

Rodrigo Bonacin, Brazil

Paolo Gaspare Bottoni, Italy

Fatma Bouali, France

Chris Bowers, UK

Giorgio Brajnik, Italy 
Anke Brock, France

Barry Brown, Sweden

Judith Brown, Canada

Gerd Bruder, Germany

Duncan Brumby, UK

Nick Bryan-Kinns, UK

Stéphanie Buisine, France

Sabin-Corneliu Buraga, Romania

Paris Buttfield-Addison, Australia

Maria Claudia Buzzi, Italy

Marina Buzzi, Italy

Cristina Cachero, Spain

Sybille Caffiau, France

Paul Cairns, UK

Roberto Caldara, Switzerland

Gaëlle Calvary, France

Licia Calvi, The Netherlands

José Campos, Portugal

Pedro Campos, Portugal

Katia Canepa Vega, Brazil

Maria-Dolores Cano, Spain

Maria Beatriz Carmo, Portugal

Francesco Carrino, Switzerland

Stefano Carrino, Switzerland

Luis Carriço, Portugal

Marcus Carter, Australia

Daniel Cernea, Germany

Teresa Chambel, Portugal

Stéphane Chatty, France

Monchu Chen, Portugal

Yu Chen, Switzerland

Kelvin Cheng, Singapore

Yoram Chisik, Portugal

Luca Chittaro, Italy

Elizabeth Churchill, USA

Torkil Clemmensen, Denmark

Gilbert Cockton, UK

Karin Coninx, Belgium

Tayana Conte, Brazil

Stéphane Conversy, France

Jeremy Cooperstock, Canada

Nuno Correia, Portugal

Joëlle Coutaz, France

Céline Coutrix, France

Nadine Couture, France

Chris Creed, UK
Martin Cronel, France

James Crowley, France

Jácome Cunha, Portugal

Paul Curzon, UK

Marie d'Udekem, Belgium

Florian Daiber, Germany

Girish Dalvi, India

José Danado, UK

Antonella De Angeli, Italy

Alexander De Luca, Switzerland

Maria De Marsico, Italy

Giorgio De Michelis, Italy

Leonardo Cunha de Miranda, Brazil

Boris De Ruyter, The Netherlands

Clarisse de Souza, Brazil

Alexandre Demeure, France

Giuseppe Desolda, Italy

Ines Di Loreto, France

Paulo Dias, Portugal

Shalaka Dighe, India

Christian Dindler, Denmark

Anke Dittmar, Germany

Pierre Dragicevic, France

Carlos Duarte, Portugal

Cathy Dudek, Canada

Henry Been-Lirn Duh, Australia

Bruno Dumas, Belgium

Sophie Dupuy-Chessa, France

Achim Ebert, Germany

Florian Echtler, Germany

Rob Edlin-White, UK

Jan Engelen, Belgium

Thomas Erickson, USA

Elina Eriksson, Sweden

Dominik Ertl, UK

Parisa Eslambolchilar, UK

Marc Fabri, UK

Carla Faria Leitão, Brazil

Ava Fatah gen Schieck, UK

Xavier Ferre, Spain

Eija Ferreira, Finland

Mirko Fetter, Germany

Sebastian Feuerstack, Germany

Vagner Figueredo de Santana, Brazil

Daniela Fogli, Italy

Joan Fons, Spain 
Manuel Fonseca, Portugal

Peter Forbrig, Germany

Marcus Foth, Australia

Andre Freire, Brazil

Carla D.S. Freitas, Brazil

Jonas Fritsch, Denmark

Luca Frosini, Italy

Dominic Furniss, UK

Nestor Garay-Vitoria, Spain

Jérémie Garcia, France

Roberto García, Spain

Jose Luis Garrido, Spain

Franca Garzotto, Italy

Isabela Gasparini, Brazil

Miguel Gea, Spain

Patrick Gebhard, Germany

Cristina Gena, Italy

Giuseppe Ghiani, Italy

Patrick Girard, France

Kentaro Go, Japan

Daniel Gonçalves, Portugal

Rúben Gouveia, Portugal

Nicholas Graham, Canada

Andrina Granic, Croatia

Toni Granollers, Spain

Saul Greenberg, Canada

John Grundy, Australia

Nuno Guimaraes, Portugal

Jan Gulliksen, Sweden

Rebecca Gulotta, USA

Mieke Haesen, Belgium

Hans Hagen, Germany

Jonna Häkkilä, Finland

Jukka Häkkinen, Finland

Jaakko Hakulinen, Finland

Lynne Hall, UK

Arnaud Hamon, France

Chris Harrison, USA

Daniel Harrison, UK

Michael Harrison, UK

Ruediger Heimgaertner, Germany

Tomi Heimonen, Finland

Matthias Heintz, UK

Ingi Helgason, UK

Susan Catherine Herring, USA

Wilko Heuten, Germany
Martin Hitz, Austria

Thuong Hoang, Australia

Rüdiger Hoffmann, Germany

Jennifer Horkoff, UK

Heiko Hornung, Brazil

Ko-Hsun Huang, Taiwan,

Republic of China

Alina Huldtgren, The Netherlands

Ebba Thora Hvannberg, Iceland

Aulikki Hyrskykari, Finland

Ioanna Iacovides, UK

Netta Iivari, Finland

Mirja Ilves, Finland

Yavuz İnal, Turkey

Poika Isokoski, Finland

Minna Isomursu, Finland

Howell Istance, Finland

Ido A. Iurgel, Germany

Mikkel R. Jakobsen, Denmark

Francis Jambon, France

Jacek Jankowski, Poland

Maddy Janse, The Netherlands

Nuno Jardim Nunes, Portugal

Caroline Jay, UK

Kasper Løvborg Jensen, Denmark

Mikael Johnson, Finland

Matt Jones, UK

Joaquim Jorge, Portugal

Rui Jose, Portugal

Anirudha Joshi, India

Christophe Jouffrais, France

Anne Joutsenvirta, Finland

Marko Jurmu, Finland

Eija Kaasinen, Finland

Jari Kangas, Finland

Anne Marie Kanstrup, Denmark

Victor Kaptelinin, Sweden

Evangelos Karapanos, Portugal

Kristiina Karvonen, Finland

Dinesh Katre, India

Manolya Kavakli, Australia

Patrick Gage Kelley, USA

Ryan Kelly, UK

Rabia Khan, UK

Hideki Koike, Japan

Christophe Kolski, France 
Hannu Korhonen, Finland

Nataliya Kosmyna, France

Paula Kotze, South Africa

Christian Kray, Germany

Per Ola Kristensson, UK

Sari Kujala, Finland

Todd Kulesza, USA

Denis Lalanne, Switzerland

David Lamas, Estonia

Michael Lankes, Austria

Rosa Lanzilotti, Italy

Przemyslaw Lasota, USA

Yann Laurillau, France

Effie Law, UK

Shaimaa Lazem, UK

Xavier Le Pallec, France

Eric Lecolinet, France

Jong-Seok Lee, South Korea

Asko Lehmuskallio, Finland

Antti Leino, Finland

Juha Leino, Finland

Tuomas Leisti, Finland

Jair Leite, Brazil

Alexander Lenz, UK

Barbara Leporini, Italy

Sophie Lepreux, France

Karen Y. Li, UK

Edirlei Lima, Brazil

James Lin, USA

Mats Lind, Sweden

Agnes Lisowska Masson, Switzerland

Zhengjie Liu, China

Sara Ljungblad, Sweden

Corrado lo Storto, Italy

Steffen Lohmann, Germany

Fernando Loizides, Cyprus

Víctor López-Jaquero, Spain

Fabien Lotte, France

Maria Dolores Lozano, Spain

Yichen Lu, Finland

Paul Lubos, Germany

Stephanie Ludi, USA

Bernd Ludwig, Germany

Andreas Luedtke, Germany

Christopher Lueg, Australia

Jo Lumsden, UK

Christof Lutteroth, New Zealand
Kris Luyten, Belgium

Anderson Maciel, Brazil

I. Scott MacKenzie, Canada

Allan MacLean, UK

Christian Maertin, Germany

Charlotte Magnusson, Sweden

Ana Gabriela Maguitman, Argentina

Päivi Majaranta, Finland

Marco Manca, Italy

Nicolai Marquardt, UK

Célia Martinie, France

Paolo Masci, UK

Masood Masoodian, New Zealand

Maristella Matera, Italy

Denys J.C. Matthies, Germany

Peter W. McOwan, UK

Gerrit Meixner, Germany

Guy Melançon, France

Amaia Mendez Zorrilla, Spain

Maria Menendez Blanco, Italy

Zdenek Mikovec, Czech Republic

Jan-Torsten Milde, Germany

Nicole Mirnig, Austria

Giulio Mori, Italy

Roxana Morosanu, UK

Christiane Moser, Austria

Marcelle Mota, Brazil

Omar Mubin, Australia

Chrystie Myketiak, UK

Miguel Nacenta, UK

Lennart Nacke, Canada

Mathieu Nancel, Canada

Bonnie Nardi, USA

David Navarre, France

Ather Nawaz, Norway

Luciana Nedel, Brazil

Alexandra Nemery, France

Vania Neris, Brazil

Daniel Nesbitt, UK

Lene Nielsen, Denmark

Anton Nijholt, The Netherlands

Laurence Nigay, France

Manuel Noguera, Spain

Monique Noirhomme, Belgium

Julianne Nyhan, UK

Clemens Nylandsted Klokmose,

Denmark 
Michael O Grady, Ireland

Aisling Ann O'Kane, UK

Marianna Obrist, UK

Lars Oestreicher, Sweden

Jarno Ojala, Finland

Patrick Oladimeji, UK

Kathia Oliveira, France

Thomas Olsson, Finland

Dan Orwa, Kenya

Nuno Otero, Sweden

Benoit Otjacques, Luxembourg

Saila Ovaska, Finland

Janne Paavilainen, Finland

Xinru Page, USA

Ana Paiva, Portugal

Jose Ignacio Panach Navarrete, Spain

Eleftherios Papachristos, Greece

Konstantinos Papoutsakis, Greece

Avi Parush, Israel

Oscar Pastor, Spain

Fabio Paternò, Italy

Celeste Lyn Paul, USA

Andriy Pavlovych, Canada

Roberto Pereira, UK

Vinícius Carvalho Pereira, Brazil

Mark J. Perry, UK

Hele Petrie, UK

Antoinio Piccinno, Italy

Lara Piccolo, UK

Emmanuel Pietriga, France

Thomas Pietrzak, France

Frank Pollick, UK

Ravi Poovaiah, India

Roman Popp, Austria

Christopher Power, UK

Raquel Prates, USA

Costin Pribeanu, Romania

Angel Puerta, USA

Kai Puolamäki, Finland

Victor M.R. Penichet, Spain

Aaron Quigley, UK

Kari-Jouko Räihä, Finland

Roope Raisamo, Finland

Venkatesh Rajamanickam, India

Nitendra Rajput, India

Ismo Rakkolainen, Finland

Jussi Rantala, Finland
Alberto Raposo, Brazil

Dimitrios Raptis, Denmark

Umar Rashid, UK

Kirsten Rassmus-Gröhn, Sweden

Matthias Rauterberg, The Netherlands

Janet Read, UK

Mandryk Regan Lee, Canada

Patrick Reignier, France

Christian Remy, Switzerland

Karen Renaud, UK

Yann Riche, USA

Fabien Ringeval, Germany

Thomas Rist, Germany

Paola Rodriguez, Colombia

Markus Rohde, Germany

Teresa Romão, Portugal

Jose Rouillard, France

Virpi Roto, Finland

Thijs Roumen, Germany

Gustavo Alberto Rovelo Ruiz, Belgium

Elisa Rubegni, Switzerland

Simon Ruffieux, Switzerland

Jaime Ruiz, USA

Angel Ruiz-Zafra, Spain

Rimvydas Ruksenas, UK

Horacio Saggion, Spain

Pascal Salembier, France

Luciana Salgado Cardoso de Castro,

Brazil

Antti Salovaara, Finland

Leonardo Sandoval, UK

Carmen Santoro, Italy

Corina Sas, UK

Andreas Savva, UK

Taufique Sayeed, Austria

Gianluca Schiavo, Italy

Antonio Giovanni Schiavone, Italy

Albrecht Schmidt, Germany

Stefan Schneegass, Germany

Kevin Schneider, Canada

Vinicius Segura, Brazil

Marcos Serrano, France

Ehud Sharlin, Canada

Sumita Sharma, Finland

Moushumi Sharmin, USA

Abhishek Shrivastava, India

Beat Signer, Belgium 
Harri Siirtola, Finland

Paula A. Silva, Ireland

Bruno S. Silva, Brazil

Carlos CL Silva, Portugal

João Carlos Silva, Portugal

Jose Luis Silva, Portugal

Paula Alexandra Silva, Ireland

Milene Silveira, Brazil

Carla Simone, Italy

Shamus Smith, Australia

Andreas Sonderegger, Switzerland

Keyur Sorathia, India

Fabio Sorrentino, Italy

Hamit Soyel, UK

Oleg Spakov, Finland

Lucio Davide Spano, Italy

Mark Vincent Springett, UK

Jan Stage, Denmark

Christian Stary, Austria

Katarzyna Stawarz, UK

Frank Steinicke, Germany

Gerald Stollnberger, Austria

Markus Stolze, Switzerland

Simone Stumpf, UK

Noi Sukaviriya, USA

Allistar Sutcliffe, UK

David Mark Swallow, UK

Tapio Takala, Finland

Chee-wee Tan, Denmark

Franck Tarpin-Bernard, France

Carlos Teixeira, Portugal

Luis Teixeira, Portugal

Daniel Tetteroo, The Netherlands

Jakob Tholander, Sweden

Nigel Thomas, UK

Liisa Tiittula, Finland

Nava Tintarev, UK

Martin Tomitsch, Australia

Ilaria Torre, Italy

Marilyn Tremaine, USA

Daniela Trevisan, Brazil

Sanjay Tripathi, India

Janice Tsai, USA

Manfred Tscheligi, Austria

Huawei Tu, UK

Outi Tuisku, Finland

Phil Turner, UK
Susan Ellen Turner, UK

Markku Turunen, Finland

Blase Ur, USA

Heli Väätäjä, Finland

Stefano Valtolina, Italy

Judy van Biljon, South Africa

Jos P. van Leeuwen, The Netherlands

Paul van Schaik, UK

Jeroen Vanattenhoven, Belgium

Jean Vanderdonckt, Belgium

Jari Varsaluoma, Finland

Radu-Daniel Vatavu, Romania

Angel Velazquez-Iturbide, Spain

Hanna Venesvirta, Finland

Jayant Venkatanathan, India

Gilles Venturini, France

Arnold Vermeeren, The Netherlands

Karel Vermeulen, UK

Frédéric Vernier, France

Markel Vigo, UK

Nadine Vigouroux, France

Chris Vincent, UK

Giuliana Vitiello, Italy

Arnd Vitzthum, Germany

Dhaval Vyas, Australia

Mike Wald, UK

Jim Wallace, Canada

Tanja Carita Walsh, Finland

Robert Walter, Germany

Leon Watts, UK

Gerhard Weber, Germany

Rina Wehbe, Canada

Astrid Weiss, Austria

Janet Louise Wesson, South Africa

Graham Wilson, UK

Stephanie Wilson, UK

Marco Winckler, France

Theophilus Winschiers, Namibia

Chui Yin Wong, Malaysia

Wolfgang Wörndl, Germany

Volker Wulf, Germany

Yeliz Yesilada, Turkey

Salu Ylirisku, Finland

Nur Haryani Zakaria, Malaysia

Massimo Zancanaro, Italy

Panayiotis Zaphiris, Cyprus

Jürgen Ziegler, Germany 
Sponsors and Supporters

Sponsors

Microsoft

Research UNIVERSITY PRESS
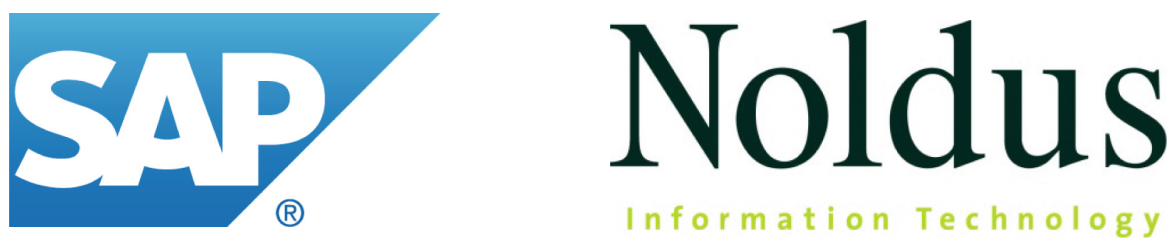

Supporters
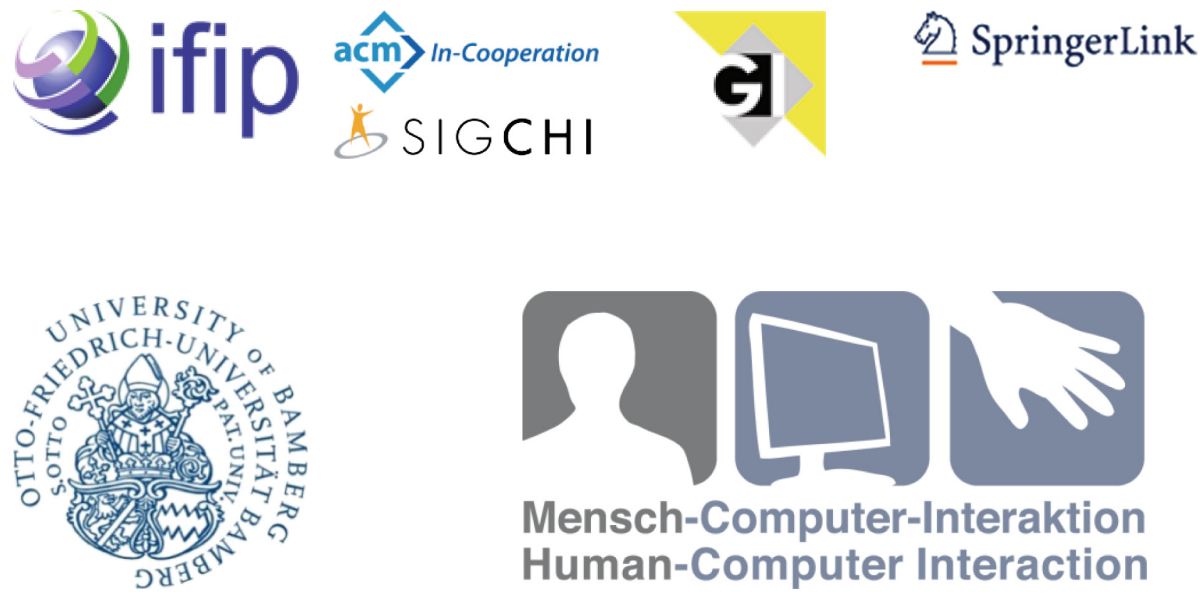

Mensch-Computer-Interaktion Human-Computer Interaction 


\section{Contents - Part III}

\section{HCI for Global Software Development}

An Interactive Approach for Inspecting Software System Measurements . . . . 1

Taimur Khan, Henning Barthel, Karsten Amrhein, Achim Ebert, and Peter Liggesmeyer

Non-response, Social Exclusion, and False Acceptance: Gatekeeping

Tactics and Usability Work in Free-Libre Open Source Software

Development ...........................

Mikko Rajanen, Netta Iivari, and Arto Lanamäki

Task Allocation Between UX Specialists and Developers in Agile Software

Development Projects . . . . . . . . . . . . . . . . . .

Kati Kuusinen

\section{HCI in Healthcare}

Breathe with Touch: A Tactile Interface for Breathing Assistance System . . .

Bin Yu, Loe Feijs, Mathias Funk, and Jun Hu

Low-Income Parents' Values Involving the Use of Technology for Accessing Health Information . . . . . . . . . . . . . . . . . . .

David Muñoz and Rosa I. Arriaga

Probing the Potential of Multimedia Artefacts to Support Communication of People with Dementia . . . . . . . . . . . . . . . . . . . . .

Alina Huldtgren, Fabian Mertl, Anja Vormann, and Chris Geiger

Smartphone-Based Gait Measurement Application for Exercise and Its Effects on the Lifestyle of Senior Citizens . . . . . . . . . . . . .

Takahiro Miura, Ken-ichiro Yabu, Atsushi Hiyama, Noriko Inamura,

Michitaka Hirose, and Tohru Ifukube

\section{HCI Studies}

Swimming the Channels: An Analysis of Online Archival Reference

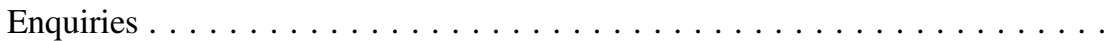

Joseph Pugh and Christopher Power

"Not Some Trumped Up Beef": Assessing Credibility of Online Restaurant Reviews. . . . . . . . . . . . . . . . . . . . . . . . .

Marina Kobayashi, Victoria Schwanda Sosik, and David Huffaker 
An Empirical Investigation of the Practices and Challenges Specific

to International User Studies. . . . . . . . . . . . . . . . . . . . .

Sabine Madsen, Lene Nielsen, Heidi Hautopp, and Iben Jensen

Entity-Centric Visualization of Open Data . . . . . . . . . . . . . . .

Sajan Raj Ojha, Mladjan Jovanovic, and Fausto Giunchiglia

Mindful Gaming: How Digital Games Can Improve Mindfulness . . . . . . . . .

Jacek Sliwinski, Mary Katsikitis, and Christian Martyn Jones

The Affordances of Broken Affordances . . . . . . . . . . . . . . .

Martin Gielsgaard Grünbaum and Jakob Grue Simonsen

\section{Human-Robot Interaction}

Deploying Robots in a Production Environment: A Study on Temporal

Transitions of Workers' Experiences . . . . . . . . . . . . . . .

Daniela Wurhofer, Thomas Meneweger, Verena Fuchsberger, and Manfred Tscheligi

Finding Objects Faster in Dense Environments Using a Projection

Augmented Robotic Arm . . . . . . . . . . . . . . . . . . . . . .

Hind Gacem, Gilles Bailly, James Eagan, and Eric Lecolinet

It's Not the Way You Look, It's How You Move: Validating a General

Scheme for Robot Affective Behaviour . . . . . . . . . . . . . . . .

Jekaterina Novikova, Gang Ren, and Leon Watts

\section{Interactive Tabletops}

HoverSpace: Analyses of the Perceived Spatial Affordances of Hover Interaction Above Tabletop Surfaces . . . . . . . . . . . . . . . . . .

Paul Lubos, Oscar Ariza, Gerd Bruder, Florian Daiber, Frank Steinicke, and Antonio Krüger

In-Situ Occlusion Resolution for Hybrid Tabletop Environments . . . . . . . . . . Jan Riemann, Mohammadreza Khalilbeigi, and Max Mühlhäuser

MovemenTable: The Design of Moving Interactive Tabletops. . . . . . . . . . .

Kazuki Takashima, Yusuke Asari, Hitomi Yokoyama, Ehud Sharlin, and Yoshifumi Kitamura

\section{Mobile and Ubiquitous Interaction}

If You Are Happy and You Know It, Say "I'm Here": Investigating Parents'

Location-Sharing Preferences . . . . . . . . . . . . . . . . .

Paolo Massa, Chiara Leonardi, Bruno Lepri, Fabio Pianesi,

and Massimo Zancanaro 
Navigation in Long Forms on Smartphones: Scrolling Worse than Tabs,

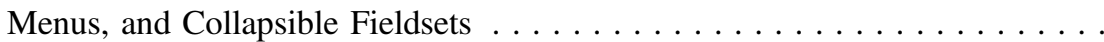

Johannes Harms, Martina Kratky, Christoph Wimmer, Karin Kappel, and Thomas Grechenig

Synchronising Live Second Screen Applications with TV Broadcasts

Through User Feedback . . . . . . . . . . . . . . . . . . . . . .

Pedro Centieiro, Teresa Romão, A. Eduardo Dias, and Rui Neves Madeira

UbiBeam: Exploring the Interaction Space for Home Deployed Projector-

Camera Systems . . . . . . . . . . . . . . . . . . . . . . .

Jan Gugenheimer, Pascal Knierim, Christian Winkler, Julian Seifert, and Enrico Rukzio

Cue Now, Reflect Later: A Study of Delayed Reflection of Diary Events. . . . Ming Ki Chong, Jon Whittle, Umar Rashid, and Chee Siang Ang

Tick that Box: Interactive Paper Documents

Yomna Abdelrahman, Thomas Kubitza, Katrin Wolf, Norman Pohl, and Albrecht Schmidt

Towards Deeper Understanding of User Experience with Ubiquitous

Computing Systems: Systematic Literature Review and Design Framework. . .

Kaisa Väänänen-Vainio-Mattila, Thomas Olsson, and Jonna Häkkilä

uCanvas: A Web Framework for Spontaneous Smartphone Interaction with Ubiquitous Displays . . . . . . . . . . . . . . . . . . . . . . .

Tilman Dingler, Tobias Bagg, Yves Grau, Niels Henze,

and Albrecht Schmidt

Wireless Smartphone Mirroring in Video Calls . . . . . . . . . . . . . . .

Henrik Sørensen, Kenton O'Hara, Phil Gosset, and Jesper Kjeldskov

\section{Mullti-screen Visualization and Large Screens}

Disperse: Enabling Web-Based Visualization in Multi-screen

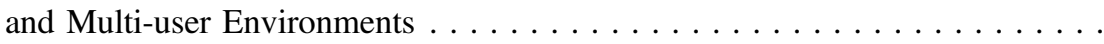

Megan Monroe and Casey Dugan

Evaluation of Distance-Aware Bimanual Manipulation Techniques

for Large High-Resolution Displays. . . . . . . . . . . . . . . . . . .

Anke Lehmann and Oliver Staadt

Should I Stay or Should I Go? Selecting Between Touch and Mid-Air

Gestures for Large-Display Interaction . . . . . . . . . . . . . . . . . . . . . .

Mikkel R. Jakobsen, Yvonne Jansen, Sebastian Boring,

and Kasper Hornboek 


\section{Participatory Design}

Funky-Design-Spaces: Interactive Environments for Creativity Inspired

by Observing Designers Making Mood Boards . . . . . . . . . . . . . .

Andrés Lucero

Kwento: Using a Participatory Approach to Design a Family Storytelling

Application for Domestic Helpers . . . . . . . . . . . . . . . .

Kakit Cheong and Alex Mitchell

Paper or Pixel? Comparing Paper- and Tool-Based Participatory Design

Approaches ............................. 501

Matthias Heintz, Effie Lai-Chong Law, and Samaneh Soleimani

Participatory Design in Practice: The Case of an Embroidered Technology. . .

Laura Cortés-Rico and Giovanny Piedrahita-Solórzano

\section{Pointing and Gesture Interaction}

Better Than You Think: Head Gestures for Mid Air Input . . . . . . . . . . . . Katrin Plaumann, Jan Ehlers, Florian Geiselhart, Gabriel Yuras, Anke Huckauf, and Enrico Rukzio

Enhancing Pinch-Drag-Flick Paradigm with Two New Gestures:

Two-Finger-Tap for Tablets and Tap\&Tap for Smartphones . . . . . . . . . . . Alessio Bellino

Estimating Production Time of Touchless Hand Drawing Gestures . . . . . . . . Orlando Erazo, José A. Pino, and Pedro Antunes

The Costs and Benefits of Combining Gaze and Hand Gestures for Remote Interaction . . . . . . . . . . . . . . . . . . . . .

Yanxia Zhang, Sophie Stellmach, Abigail Sellen, and Andrew Blake

\section{Social Interaction}

Sharing Wishes on Public Displays: Using Technology to Create Social Places . . . . . . . . . . . . . . . . . . . . . . . .

Vinicius Ferreira, Junia Anacleto, and Andre Bueno

Social Interaction Design Patterns for Urban Media Architecture. . . . . . . . . . Luke Hespanhol and Peter Dalsgaard

Thinking Like Disney: Supporting the Disney Method Using Ambient Feedback Based on Group Performance . . . . . . . . . . . . . . . . . Sarah Tausch, Fabius Steinberger, and Heinrich Hußmann 
Eery Space: Facilitating Virtual Meetings Through Remote Proxemics. . . . . 622 Maurício Sousa, Daniel Mendes, Alfredo Ferreira, João Madeiras Pereira, and Joaquim Jorge 